\title{
COVID-19 (SARS-CoV-2) Infection in Pregnancy: A Systematic Review
}

\author{
Hubba Akhtar ${ }^{\mathrm{a}}$ Chandni Patel $^{\mathrm{a}}$ Eyad Abuelgasim ${ }^{\mathrm{b}}$ Amer Harky ${ }^{\mathrm{c}, \mathrm{d}}$ \\ aDepartment of Medicine, St George's, University of London, London, UK; ${ }^{\text {b} F a c u l t y ~ o f ~ M e d i c i n e, ~ I m p e r i a l ~ C o l l e g e ~}$ \\ London, London, UK; 'Department of Cardiothoracic Surgery, Liverpool Heart and Chest Hospital, Liverpool, UK; \\ ${ }^{\mathrm{d}}$ Department of Integrative Biology, Faculty of Life Science, University of Liverpool, Liverpool, UK
}

\section{Keywords}

Coronavirus disease 2019 · Pregnancy · Foetus · Vertical transmission · Preterm delivery

\begin{abstract}
Introduction: To review published studies related to the association of severe acute respiratory syndrome coronavirus 2 (SARS-CoV-2) infections with pregnancy, foetal, and neonatal outcomes during coronavirus disease 2019 (COVID-19) pandemic in a systematic manner. Methods: A comprehensive electronic search was done through PubMed, Scopus, Medline, Cochrane database, and Google Scholar from December 01, 2019, to May 22, 2020, along with the reference list of all included studies. All cohort studies that reported on outcomes of COVID-19 during pregnancy were included. Qualitative assessment of included studies was performed using the Newcastle-Ottawa scale. Results: Upon admission, most pregnant women underwent a low-dose radiation CT scan; the reports of which included unilateral/bilateral pneumonia in most patients. A marked lymphopenia was also noted in many patients with COVID-19. 513 titles were screened, and 22 studies were included, which identified 156 pregnant women with COVID-19 and 108 neonatal outcomes. The most common maternal/foetal complications in-
\end{abstract}

cluded intrauterine/foetal distress (14\%) and premature rupture of membranes (8\%). The neonatal clinical manifestations of COVID-19 commonly included shortness of breath (6\%), gastrointestinal symptoms (4\%), and fever (3\%). Conclusion: COVID-19 infection in pregnancy leads to increased risk in pregnancy complications such as preterm birth, PPROM, and may possibly lead to maternal death in rare cases. There is no evidence to support vertical transmission of SARS-CoV-2 infection to the unborn child. Due to a paucity of inconsistent data regarding the impact of COVID-19 on the newborn, caution should be undertaken to further investigate and monitor possible infection in the neonates born to COVID-19-infected mothers. @ 2020 The Author(s)

Published by S. Karger AG, Basel

\section{Introduction}

The current coronavirus disease 2019 (COVID-19) pneumonia pandemic, caused by the severe acute respiratory syndrome coronavirus 2 (SARS-CoV-2), has become a major global health threat. Since its first identification in Wuhan, China, in December 2019, COVID-19 has spread globally at an accelerated rate with rapid increases in cases and mortality $[1,2]$.

\begin{tabular}{ll}
\hline karger@karger.com & $\begin{array}{l}\text { (c) 2020 The Author(s) } \\
\text { Published by S. Karger AG, Basel } \\
\text { www.karger.com/goi }\end{array}$ \\
Karger & $\begin{array}{l}\text { This article is licensed under the Creative Commons Attribution 4.0 } \\
\text { International License (CC BY) (http://www.karger.com/Services/ } \\
\text { OpenAccessLicense). Usage, derivative works and distribution are } \\
\text { permitted provided that proper credit is given to the author and the } \\
\text { original publisher. }\end{array}$
\end{tabular}


Table 1. Newcastle-Ottawa scale table

\begin{tabular}{|c|c|c|c|c|c|c|c|c|}
\hline Author & \multicolumn{4}{|l|}{ Selection } & $\begin{array}{l}\text { Comparability } \\
\text { Reporting of } \\
\text { pregnant } \\
\text { patient }={ }^{*} \text { foetus }=*\end{array}$ & \multicolumn{3}{|l|}{ Outcomes } \\
\hline Liu et al. [4] & * & $*$ & * & $*$ & $* *$ & $*$ & * & * \\
\hline Chen et al. [5] & $*$ & $*$ & $*$ & $*$ & $* *$ & $*$ & * & $*$ \\
\hline Zhu et al. [6] & $*$ & $*$ & * & $*$ & $* *$ & $*$ & $*$ & $*$ \\
\hline Wang et al. [12] & $*$ & $*$ & $*$ & $*$ & $* *$ & * & * & * \\
\hline Liu et al. [13] & $*$ & $*$ & $*$ & $*$ & $* *$ & * & & * \\
\hline Yu et al. [14] & $*$ & $*$ & $*$ & $*$ & $* *$ & $*$ & $*$ & $*$ \\
\hline Li et al. [15] & $*$ & $*$ & $*$ & * & $* *$ & * & $*$ & * \\
\hline Fan et al. [16] & $*$ & $*$ & $*$ & * & $* *$ & * & * & $*$ \\
\hline Wang et al. [17] & $*$ & $*$ & * & $*$ & $* *$ & * & $*$ & $*$ \\
\hline Karami et al. [22] & * & $*$ & $*$ & $*$ & $* *$ & * & $*$ & $*$ \\
\hline Hantoushzadeh et al. [29] & * & * & $*$ & * & $* *$ & * & * & * \\
\hline Baud et al. [30] & * & * & $*$ & * & $* *$ & * & * & * \\
\hline Shanes et al. [31] & * & * & * & * & $*$ & $*$ & $*$ & \\
\hline Penfield et al. [33] & $*$ & * & * & * & * & * & * & \\
\hline Gidlöf et al. [34] & $*$ & * & $*$ & * & $* *$ & * & $*$ & * \\
\hline Chen et al. [35] & * & * & * & * & ** & * & * & * \\
\hline Breslin et al. [36] & * & * & $*$ & $*$ & $* *$ & $*$ & & \\
\hline
\end{tabular}

COVID-19, coronavirus disease 2019.

Viral pneumonia is one of the leading causes of pregnancy deaths worldwide [3]. Physiological changes during pregnancy, such as reduced functional residual volumes, diaphragm elevation, and oedema of respiratory tract mucosa, as well as changes in cell immunity can lead to increased susceptibility to viral infections and can have worsened outcomes [4]. However, to date, there are limited studies pertaining to the outcomes of COVID-19 during pregnancy, differences in clinical course, and the potential risks to the unborn child. Studies have so far shown that the clinical, radiological, and laboratory characteristics of COVID-19 pneumonia in pregnant women are similar to those reported for nonpregnant patients [5-10]. Moreover, currently there has been no evidence of intrauterine vertical transmission of SARS-CoV-2 infection in pregnant women with COVID-19 [5-10].

\section{Methods}

\section{Literature Search}

This study was done according to Preferred Reporting Items for Systematic Reviews and Meta-Analyses (PRISMA) method identifying published literature on COVID-19 and its potential impact on pregnancy and neonates. The comprehensive literature search was carried out with PubMed, Medline, Scopus, Cochrane database, and Google Scholar, using key MeSH words, which include "COVID-19," "Pregnancy," "Coronavirus 2019," "Newborn," "Foetus," "Neonate," "vertical transmission," and "outcomes." All published articles have been reviewed, and the findings have been included in this study. The relevant articles have been cited and referenced within this study. The limits included studies in English and articles published after December 2019 until May 22, 2020. All the relevant articles identified were analysed by 2 authors, and the results were appropriately summarised and reported.

\section{Inclusion and Exclusion Criteria}

The key inclusion criteria were articles that reported on outcomes of COVID-19 during pregnancy, and studies were excluded if no cohort outcomes were observed. Other exclusion criteria were consensus documents, editorials, commentaries, and narrative reviews. 


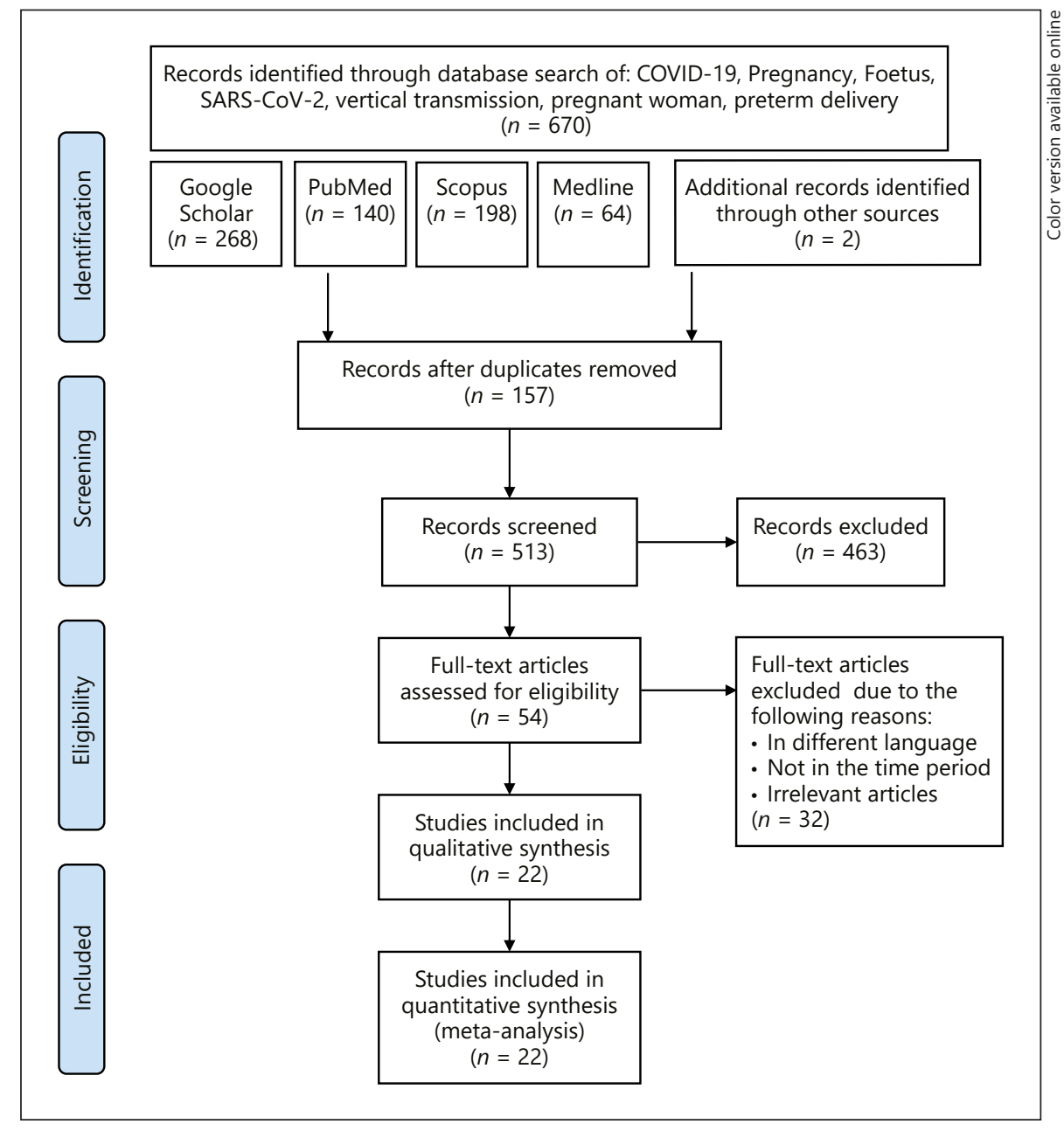

Fig. 1. PRISMA flow diagram.

\section{Results}

All studies were screened by 2 authors independently (H.A. and C.P.); disagreement was resolved by consensus or involvement of other authors (E.A. and A.H.). The extracted data then were crosschecked by a third author to validate their accuracy (E.A.).

Methodological Quality Assessment of Included Studies

Qualitative assessment of included studies was performed using the Newcastle-Ottawa scale [11] (Table 1). The Newcastle-Ottawa scale was devised specifically to assess the quality of nonrandomised studies included in systematic reviews and meta-analyses. It assesses bias of each study using a star-based rating system, with a maximum score of 9 indicating lowest risk of bias and a minimum of 0 indicating highest risk. Scores $\geq 7$ generally represent a low risk of substantial bias. Quality of included studies was rated by 2 reviewers (H.A. and C.P.). Discrepancies were resolved by consensus.

\section{Statistical Analysis}

It was not possible to do pooled analysis due to lack of consistent data within the current reported studies.
Following an extensive database search, a total of 670 were found initially, and after full text screening, only 22 studies met the inclusion criteria [4-7, 12-25] (Fig. 1), identifying 156 pregnant women with COVID-19 and 108 neonatal outcomes. Table 2 includes the summarised key findings of the studies included in this review.

\section{Analysis of the Reports}

A total of 156 pregnant women with COVID-19 have been identified and 108 newborns (including 4 sets of twins and 10 foetal deaths) have been included in this review. The maternal ages ranged from 22 to 42 years. Sixtysix caesarean sections and 19 normal vaginal deliveries were identified. The remaining included pregnant women who have not yet given birth and unrecorded data in individual studies. Twenty-seven preterm deliveries have been recorded. 


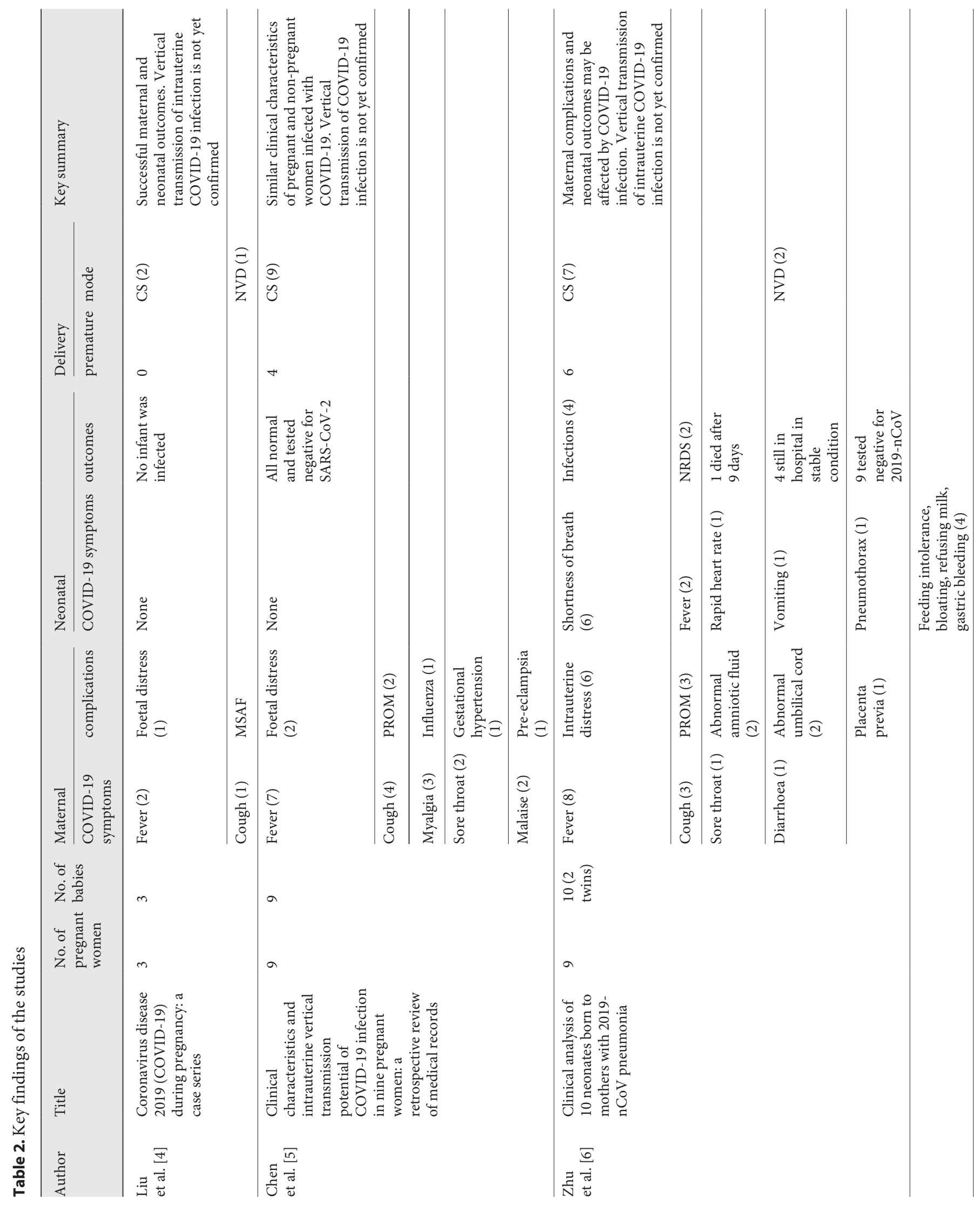




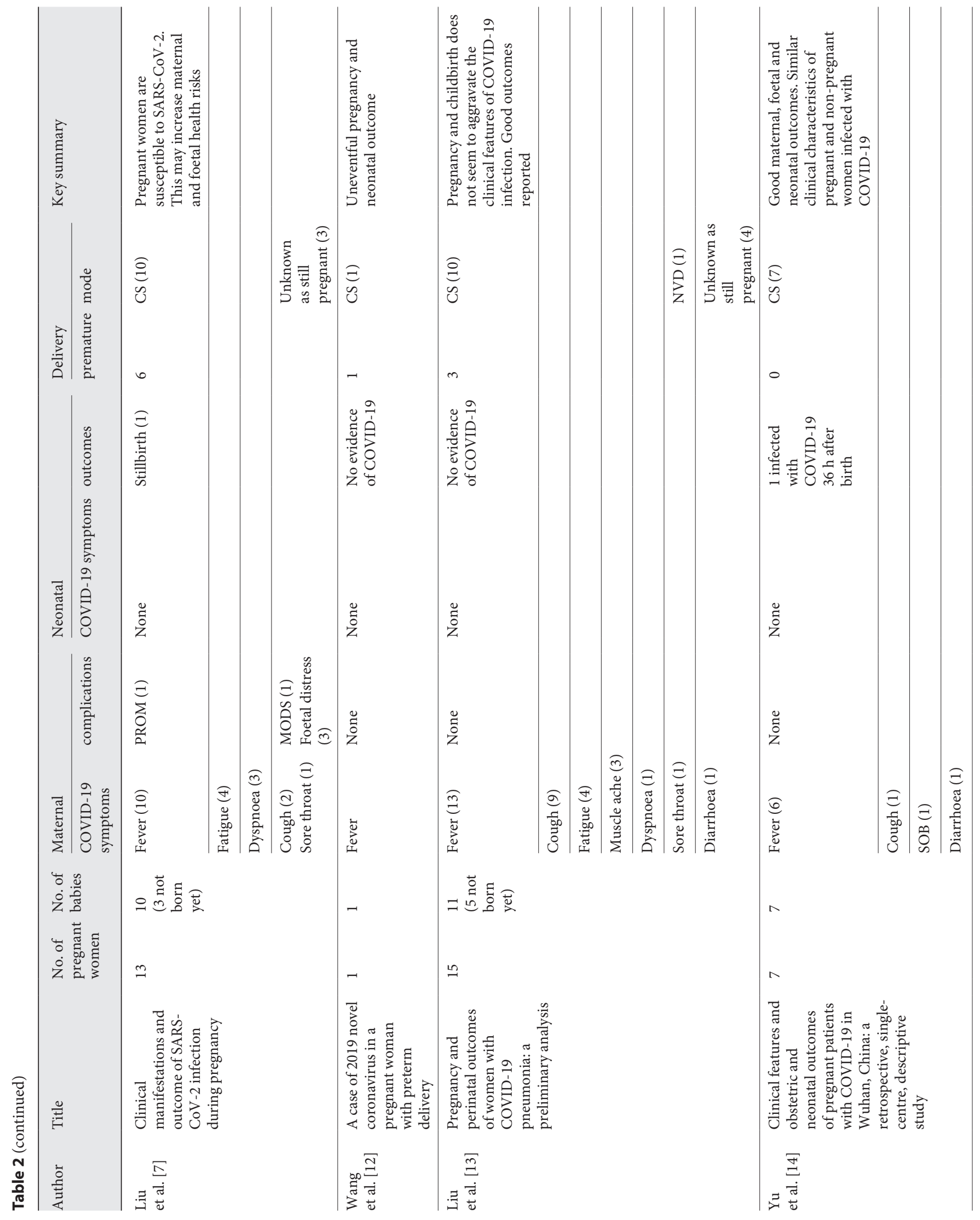




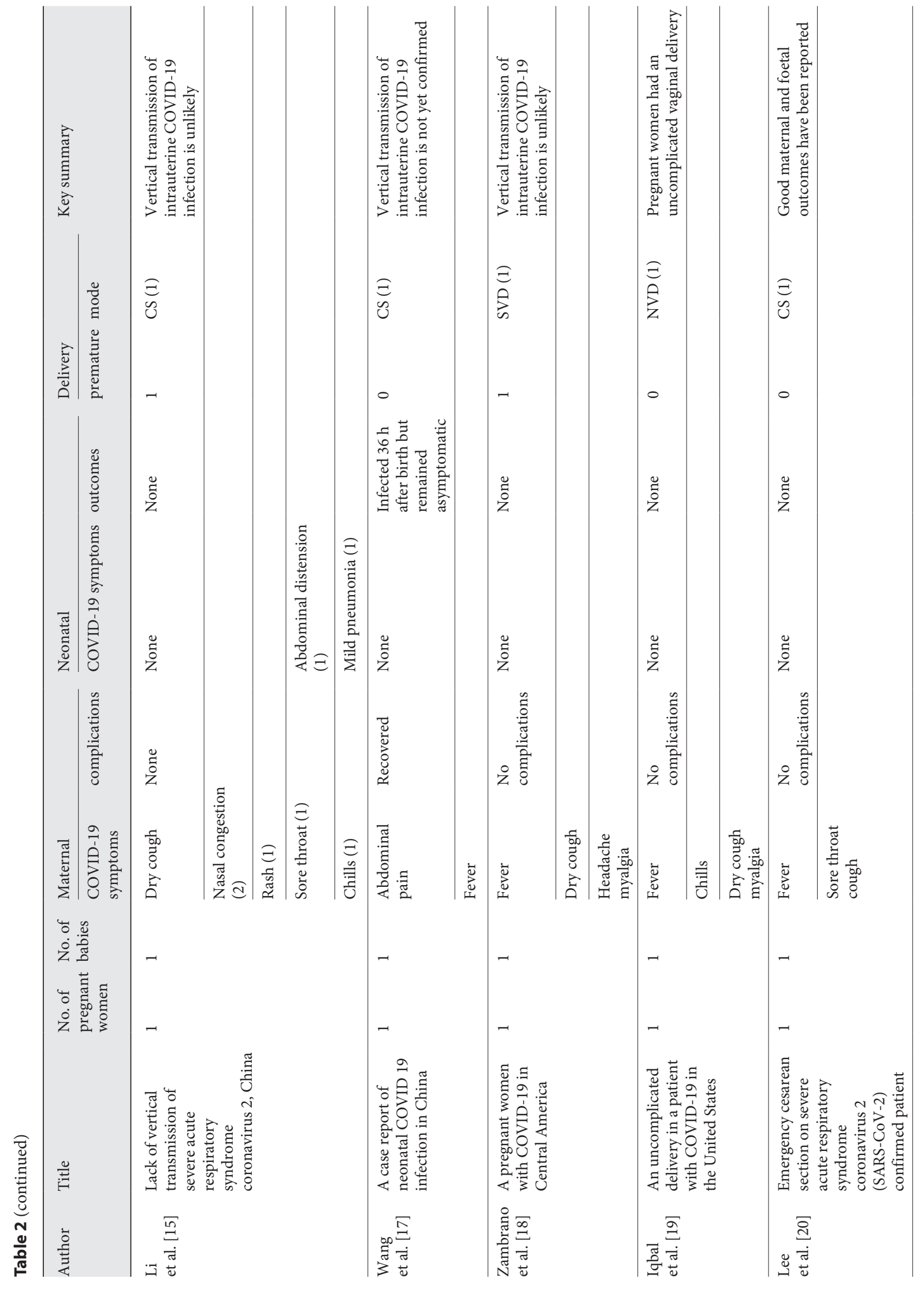




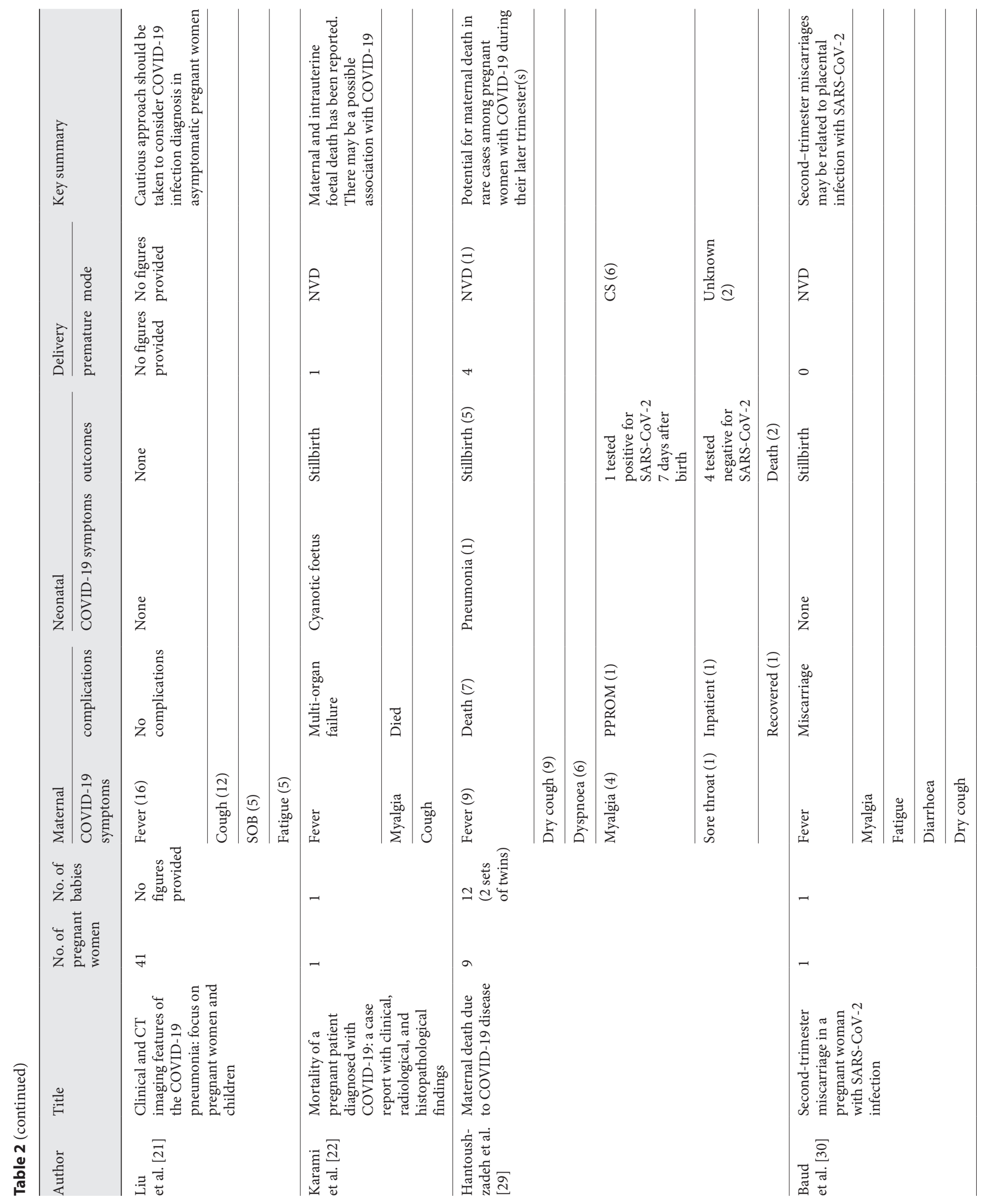




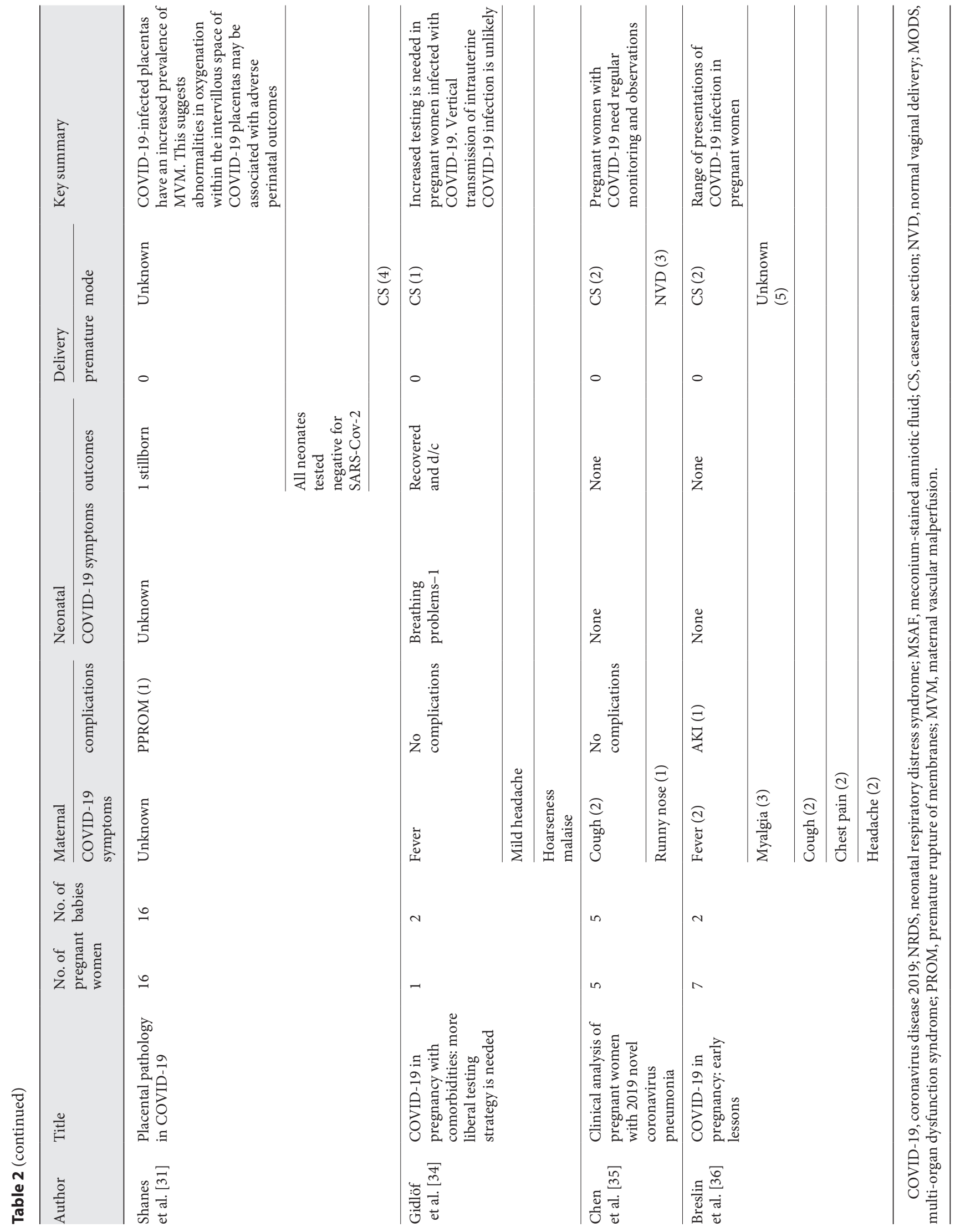


Most of the mothers received nasal oxygen therapy; however, 11 patients were reported to receive intubation and mechanical ventilation. Many of the pregnant women received antiviral and antibiotic medications. A study by Yu et al. [14] reported the use of traditional Chinese medications in all 7 of their patients. Maternal clinical manifestations reported were fever (53\%), cough (32\%), fatigue/malaise (13\%), myalgia (11\%), sore throat (5\%), and shortness of breath (8\%). Upon admission, most pregnant women underwent a low-dose radiation CT scan; the reports of which included unilateral/bilateral pneumonia in most patients. A marked lymphopenia was also noted in many patients with COVID-19. The most common maternal/foetal complications included intrauterine/foetal distress (14\%) and premature rupture of membranes (PROM) $(8 \%)$. The neonatal clinical manifestations of COVID-19 commonly included shortness of breath (6\%), gastrointestinal symptoms (4\%), and fever (3\%).

\section{Discussion}

\section{Impact of COVID-19 on Pregnancy}

The health of pregnant women needs to be taken into account during this rapidly changing coronavirus pandemic. It is important to provide critical interventions necessary for pregnant women. These carefully evaluated decisions must be extensively discussed while considering both maternal and foetal outcomes in the context of the potential impact of COVID-19 on the pregnancy.

World Health Organisation (WHO) has reported that there is no apparent difference in the risk of developing clinical symptoms between non-pregnant and pregnant women of reproductive age $[5,26]$. It seems the latter is also not at a higher risk of developing severe disease. Patients most commonly present with mild symptoms of the infection including fever, cough, fatigue, and shortness of breath; however, some may be asymptomatic [4$7,12-20]$. In a retrospective review by Liu et al. [21], a comparison of 59 patients, which included both pregnant and non-pregnant adults, was carried out. This review reported no significant difference between the various groups regarding the development of the clinical features of SARS-CoV-2.

Pregnant women undergo physiological changes, which lead to altered immune systems [27]. This does not necessarily make them more susceptible to viral infection; hence, their response to COVID-19 may be similar to any other viral infection. However, due to the modulated immune system, they may experience severe symptoms, al- beit there is a low probability of this happening. According to 1 study, pregnancy itself does not worsen the symptoms experienced, nor the findings on a CT scan of COVID-19 related pneumonia [4].

Given the novelty of COVID-19, not enough evidence is available to conclude the definite effect of this virus during pregnancy. Comparison to other coronavirus infections, such as SARS and MERS, may provide a possible indication of the outcome of the COVID-19 virus process $[22,28]$. Three studies have reported no maternal complications, such as postpartum COVID-19 infection and preterm labour $[5,12,14]$. However, various other studies have reported both maternal and foetal complications including preterm delivery, respiratory distress, foetal distress, and PROM [6]. Additionally, a case report published in Iran has stated 1 maternal death and subsequently 1 intrauterine foetal death, which has been directly linked to the COVID-19 infection during the third trimester [22]. In an adjudicated case series from Iran, 9 pregnant women diagnosed with severe COVID-19 disease during their later second or third trimester were identified. At the time of reporting, 7 of 9 died, 1 of 9 remained critically ill and ventilator-dependent, and 1 of 9 recovered after prolonged hospitalisation [29]. Moreover, Baud et al. [30] reported a case of miscarriage during the second trimester of pregnancy in a woman with COVID-19, which appeared to be related to placental infection with SARS-CoV-2.

Shanes et al. [31] examined the placentas of 16 women with severe COVID-19 infection (15 live births in the third trimester and 1 delivered in the second trimester after intrauterine foetal demise). The study found that pregnant women who were infected with COVID-19 and delivered in the third trimester were more likely to have placentas that show features of maternal vascular malperfusion and intervillous thrombi. No pathognomonic features were identified; however, these findings suggest abnormal maternal circulation that is associated with adverse perinatal outcomes. These changes may reflect a systemic inflammatory or hypercoagulable state influencing placental physiology. Shanes et al. [31] notes that increased antenatal surveillance for women with COVID-19 may be warranted.

According to the Royal College of Obstetricians and Gynaecologists (RCOG), vertical transmission from the woman to her baby may be possible, as suggested by new evidence [27]. A few emerging studies have reported the probability of in utero COVID-19 transmission by measuring the foetal IgM blood level $[16,23,32]$. The IgM antibody is not transferred via the placenta; therefore, it 
is suggested that this may possibly be the foetal immune response to the infection. One study reported COVID-19 infection in a neonate $36 \mathrm{~h}$ after birth [14]. Further tests looking into the probability of intrauterine transmission concluded negative results for SARS-CoV-2 nucleic acid test of the placenta and cord blood in that particular patient. This is further supported by earlier case reports from China, which have provided evidence that suggests no correlation of vertical transmission. These reports have also mentioned negative COVID-19 results of samples obtained from the infected women's amniotic fluid, cord blood, genital swabs, and breast milk, and the neonatal throat swabs; therefore, all the neonates have tested negative so far [5, 6, 24, 25]. However, Penfield et al. [33] have reported a study in which of 11 placental or membrane swabs sent following delivery, 3 swabs were positive for SARS-CoV-2, all in women with moderate to severe COVID-19 illness at time of delivery. This is the first study to demonstrate the presence of SARS-CoV-2 RNA in placental or membrane samples. Whilst there were no clinical signs of vertical transmission, their findings raise the possibility of intrapartum viral exposure. Therefore, caesarean deliveries would be the recommended mode of delivery to decrease length of exposure to these tissues and thus decrease likelihood of possible vertical transmission. Taking all available evidence into consideration, there are only a small number of reported cases to conclude whether there is an intrauterine vertical transmission of SARS-CoV-2. Therefore, stating any definitive outcome is not possible at this point in time. Data collection from MBRRACE-UK has recently been established for which monitoring of affected women and their newborns is being carried out [27]. This will hopefully provide useful data collection and help support outcomes for future reports. Furthermore, a larger case series is needed to define the relationship between SARS-CoV-2, acute inflammation, and intrauterine foetal demise.

\section{Impact of COVID-19 on the Foetus}

According to RCOG, there is currently not enough data to provide a correlation between the risk of miscarriage and COVID-19 or that the virus is teratogenic [27]. The possibility of vertical transmission needs further research as there have been conflicting results so far. Foetal outcomes, where there is evidence of maternal COVID-19 infection, have been reported to include foetal and respiratory distress in utero, PROM, and premature delivery $[4-7,13,15,18,22]$. However, whether the preterm delivery is due to iatrogenic aetiology or other causes, it needs to be further investigated for a definitive answer [27].

\section{Impact of COVID-19 on the Newborn}

Many studies reported asymptomatic newborns, born to mothers with COVID-19 infection. One study by Zhu et al. [6] has reported neonatal COVID-19 symptoms to include shortness of breath, fever, and gastrointestinal symptoms such as vomiting and abdominal distension. Study by Fan et al. [16] also reported similar symptoms.

There have been promising results shown across many studies in this systematic review regarding neonatal outcomes $[5,6,13]$. Most of the symptoms experienced by the neonates were regularly monitored and managed with conservative treatment from which the babies recovered well. A study by Yu et al. [14] reported 7 pregnant women positive for SARS-CoV-2. Following their caesarean sections, the infants suspected of a possible COVID-19 infection were also tested. Only 1 neonate was identified as positive at $36 \mathrm{~h}$ after birth, with mild shortness of breath symptoms. Following this, the infant recovered well and was subsequently discharged from hospital.

Some studies have reported unfavourable neonatal outcomes. It is important to consider blood test results in conjunction with SARS-CoV-2 nucleic acid test due to the higher false-negative rate in the latter and the asymptomatic presentation of many neonates [6]. Zhu et al. [6] described 10 neonates that tested negative for SARS-CoV-2. However, 2 neonates had thrombocytopenia and abnormal liver function tests; following which 1 neonate fully recovered, but 1 neonate died. The death of the neonate is assumed to have been precipitated by various different factors including poor immune function, refractory shock due to major viraemia, multiple organ failure, and disseminated intravascular coagulation. Therefore, it was concluded that false negatives of the SARS-CoV-2 nucleic acid test could not be ruled out. Fan et al. [16] have reported lymphopenia and mild pneumonia findings in 2 neonates, with no significant clinical features, born to infected mothers. This was further supported by Wang et al. [17], who reported deranged liver function tests and lymphopenia in an asymptomatic neonate born to SARS-CoV-2 infected mother. Neonatal deaths have been reported by Karami et al. [22] and Liu et al. [7], where unfavourable pregnancy characteristics including maternal multiple organ dysfunction syndrome are thought to be associated with the poor neonatal outcomes. Therefore, caution should be undertaken to further investigate and monitor possible infection in the neonates born to COVID-19-infected mothers. 


\section{Future Studies}

The potential transmission of COVID-19 through breast milk is unknown. Large studies are needed to determine whether COVID-19 can be transmitted to newborns through breast milk from their infected mother. Currently, no data have supported that SARS-CoV-2 could be transmitted through breast milk. Chen et al. [5] tested for SARS-CoV-2 in breast milk samples from 6 infected patients, and all samples tested negative for the virus. Therefore, while this suggests that human milk does not act as a vehicle for COVID-19, further studies with larger sample sizes are recommended. Future studies should also assess whether there is a risk of ascending infection during labour by testing for SARS-COV-2 in intrapartum vaginal secretion samples, placental tissue, and amniotic fluid and amnion-chorion interface swap samples.

Longitudinal studies and clinical analysis are needed to assess the clinical course of infants born to infected mothers. Furthermore, maternal inflammation in response to SARS-COV-2 infection could have adverse effects on the developing foetus [37]. More studies in this area are recommended [38-40].

\section{Conclusion}

Given the novelty of COVID-19, data on the effect of COVID-19 on pregnancy, the foetus, and the newborn are so far limited to a few small case series. Nevertheless, while pregnant women do better than the population aged 80 years and above, they have twice the higher rate of PPROM and 3 times the higher rate of preterm births compared to the general pregnant population. There is not enough evidence to support vertical transmission of SARS-CoV-2 infection to the unborn child. Due to a paucity of inconsistent data regarding the impact of COVID-19 on the newborn, caution should be undertaken to further investigate and monitor possible infection in the neonates born to COVID-19-infected mothers.

\section{Statement of Ethics}

This work has been carried ut in compliance with the PRISMA guidelines.

\section{Conflict of Interest Statement}

The authors have no conflicts of interest to declare.

\section{Funding Sources}

The authors did not receive any funding.

\section{Author Contributions}

H.A.: planned the work, conducted literature search, wrote the manuscript, reported the work, and responsible for the overall work content. C.P.: planned the work, conducted literature search, wrote the manuscript, reported the work, and responsible for the overall work content. E.A.: planned the work, conducted literature search, wrote the manuscript, reported the work, and responsible for the overall work content. A.H.: planned the work, supervised the literature search, reviewed and edited the written manuscript, supervised the reported work, and responsible for the overall work content.

\section{References}

1 Huang C, Wang Y, Li X, Ren L, Zhao J, Hu Y, et al. Clinical features of patients infected with 2019 novel coronavirus in Wuhan, China. Lancet. 2020;395:497-506.

2 Abuelgasim E, Saw L, Shirke M, Zeinah M, Harky A. COVID-19: Unique public health issues facing Black, Asian and minority ethnic communities. Curr Probl Cardiol. 2020;45(8): 100621. 10.1016/j.cpcardiol.2020.100621.

3 Dashraath P, Jing Lin Jeslyn W, Mei Xian Karen L, Lim ML, Li S, Biswas A, et al. Coronavirus disease 2019 (COVID-19) pandemic and pregnancy. Am J Obstet Gynecol. 2020; 222(6):521-31

4 Liu W, Wang Q, Zhang Q, Chen L, Chen J, Zhang B, et al. Coronavirus disease 2019 (COVID-19) during pregnancy: a case series. 2020.
5 Chen H, Guo J, Wang C, Luo F, Yu X, Zhang $\mathrm{W}$, et al. Clinical characteristics and intrauterine vertical transmission potential of $\mathrm{CO}$ VID-19 infection in nine pregnant women: a retrospective review of medical records. Lancet. 2020;395:809-15.

6 Zhu H, Wang L, Fang C, Peng S, Zhang L, Chang $\mathrm{G}$, et al. Clinical analysis of 10 neonates born to mothers with 2019-nCov pneumonia. Transl Pediatr. 2020;9:51-60.

7 Liu Y, Chen H, Tang K, Guo Y. Clinical manifestations and outcome of SARS-CoV-2 infection during pregnancy. J Infect. 2020.

8 Zhang L, Jiang Y, Wei M, Chen BH, Zhou XC, $\mathrm{Li}$ J, et al. [Analysis of the pregnancy outcomes in pregnant women with COVID-19 in Hubei Province]. Zhonghua Fu Chan Ke Za Zhi. 2020;55:166.
9 Lei D, Wang C, Li C, Fang C, Yang W, Chang $\mathrm{B}$, et al. Clinical characteristics of COVID-19 in pregnancy: analysis of nine cases. Chin J Perinat Med. 2020;23(03):159-65.

10 Yan J, Guo J, Fan C, Juan J, Yu X, Li J, et al. Coronavirus disease 2019 (COVID-19) in pregnant women: a report based on 116 cases. Am J Obstet Gynecol. 2020.

11 Wells G, Shea B, O'Connell D, Peterson J, Welch V, Losos M, et al. The NewcastleOttawa Scale (NOS) for assessing the quality of nonrandomised studies in meta-analyses. 2020 .

12 Wang X, Zhou Z, Zhang J, Zhu F, Tang Y, Shen X. A case of 2019 novel coronavirus in a pregnant woman with preterm delivery. Clin Infect Dis. 2020 
13 Liu D, Li L, Wu X, Zheng D, Wang J, Yang $\mathrm{L}$, et al. Pregnancy and perinatal outcomes of women with coronavirus disease (COVID-19) pneumonia: a preliminary analysis. Am J Roentgenol. 2020;215:1-6.

14 Yu N, Li W, Kang Q, Xiong Z, Wang S, Lin X, et al. Clinical features and obstetric and neonatal outcomes of pregnant patients with $\mathrm{CO}$ VID-19 in Wuhan, China: a retrospective, single-centre, descriptive study. Lancet Infect Dis. 2020;20(5):559-64.

15 Li Y, Zhao R, Zheng S, Chen X, Wang J, Sheng $X$, et al. Lack of vertical transmission of severe acute respiratory syndrome coronavirus 2, China. Emerg Infect Dis. 2020;26(6):1335-6.

16 Fan C, Lei D, Fang C, Li C, Wang M, Liu Y, et al. Perinatal transmission of COVID-19 associated SARS-CoV-2: should we worry? Clin Infect Dis. 2020.

17 Wang S, Guo L, Chen L, Liu W, Cao Y, Zhang $\mathrm{J}$, et al. A case report of neonatal 2019 coronavirus disease in China. Clin Infect Dis. 2020.

18 Zambrano L, Fuentes-Barahona I, BejaranoTorres D, Bustillo C, Gonzales G, VallecilloChinchilla G, et al. A pregnant woman with COVID-19 in Central America. Travel Med Infect Dis. 2020;101639.

19 Iqbal S, Overcash R, Mokhtari N, Saeed H, Gold S, Auguste T, et al. An uncomplicated delivery in a patient with COVID-19 in the United States. N Engl J Med. 2020;382(16): e34.

20 Lee D, Lee J, Kim E, Woo K, Park H, An J. Emergency cesarean section on severe acute respiratory syndrome coronavirus 2 (SARS$\mathrm{CoV}-2$ ) confirmed patient. Korean J Anesthesiol. 2020.

21 Liu H, Liu F, Li J, Zhang T, Wang D, Lan W. Clinical and CT imaging features of the COVID-19 pneumonia: focus on pregnant women and children. J Infect. 2020;80(5):e7-e13.
22 Karami P, Naghavi M, Feyzi A, Aghamohammadi M, Novin MS, Mobaien A, et al. Mortality of a pregnant patient diagnosed with COVID-19: a case report with clinical, radiologi$\mathrm{cal}$, and histopathological findings. Travel Med Infect Dis. 2020:101665.

23 Zeng H, Xu C, Fan J, Tang Y, Deng Q, Zhang $\mathrm{W}$, et al. Antibodies in infants born to mothers with COVID-19 pneumonia. JAMA. 2020; 323(18):1848-49.

24 Chen Y, Peng H, Wang L, Zhao Y, Zeng L, Gao H, et al. Infants born to mothers with a new coronavirus (COVID-19). Front Pediatr. $2020 ; 8$.

25 Li N, Han L, Peng M, Lv Y, Ouyang Y, Liu K, et al. Maternal and neonatal outcomes of pregnant women with COVID-19 pneumonia: a case-control study. Clin Infect Dis. 2020.

26 Aylward B, Liang W, Dong X, Eckmanns T, Fisher D, Ihekweazu C. Report of the WHOChina joint mission on coronavirus disease 2019 (COVID-19) [Internet]. Beijing: World Health Organisation; 2020.

27 Coronavirus (COVID-19) Infection in Pregnancy|Guidance |RCOG [Internet]. Rcog.org.uk. 2020 [cited 29 April 2020]. Available from: https://www.rcog.org.uk/ globalassets/documents/guidelines/2020-04-17-coronavirus-covid-19-infection-inpregnancy.pdf.

28 Mullins E, Evans D, Viner R, O’Brien P, Morris $\mathrm{E}$. Coronavirus in pregnancy and delivery: rapid review. Ultrasound Obstet Gynecol. 2020;55(5):586-92.

29 Hantoushzadeh S, Shamshirsaz AA, Aleyasin A, Seferovic MD, Aski SK, Arian SE, et al. Maternal death due to COVID-19 disease. Am J Obst Gynecol. 2020.

30 Baud D, Greub G, Favre G, Gengler C, Jaton $\mathrm{K}$, Dubruc E, et al. Second-trimester miscarriage in a pregnant woman with SARS-CoV-2 Infection. JAMA. 2020;323(21):2198-200.
31 Shanes ED, Mithal LB, Otero S, Azad HA, Miller ES, Goldstein JA. Placental pathology in COVID-19. Am J Clin Pathol. 2020;154(1): 23-32.

32 Dong L, Tian J, He S, Zhu C, Wang J, Liu C, et al. Possible vertical transmission of SARSCoV-2 from an infected mother to her newborn. JAMA. 2020;323(18):1846-48.

33 Penfield CA, Brubaker SG, Limaye MA, Lighter J, Ratner AJ, Thomas KM, et al. Detection of SARS-COV-2 in placental and fetal membrane samples. Am J Obstet Gynecol MFM. 2020;100133.

34 Gidlöf S, Savchenko J, Brune T, Josefsson H. COVID-19 in pregnancy with comorbidities: More liberal testing strategy is needed. Acta Obstet Gynecol Scand. 2020

35 Chen S, Liao E, Cao D, Gao Y, Sun G, Shao Y. Clinical analysis of pregnant women with 2019 novel coronavirus pneumonia. J Med Virol. 2020

36 Breslin N, Baptiste C, Miller R, Fuchs K, Goffman D, Gyamfi-Bannerman C, et al. COVID-19 in pregnancy: early lessons. Am J Obstet Gynecol MFM. 2020;2:100111.

37 Mor G. The unique immunological and microbial aspects of pregnancy. Nat Rev Immunol. 2017;17:469-82.

38 COVIDSurg Collaborative. Mortality and pulmonary complications in patients undergoing surgery with perioperative SARSCoV-2 infection: an international cohort study. Lancet. 2020. 10.1016/S0140-6736 (20)31182-X. 32479829.

39 Zaim S, Chong JH, Sankaranarayanan V, Harky A. COVID-19 and Multiorgan Response.CurrProblCardiol.2020;45(8):100618. 10.1016/j.cpcardiol.2020.100618. 32439197.

40 Kermali M, Khalsa RK, Pillai K, Ismail Z, Harky A. The role of biomarkers in diagnosis of COVID-19 - A systematic review. Life Sci. 2020;254:117788. 10.1016/j.lfs.2020.117788. 32475810 . 